\title{
MIL ROSAS HOMO-BIO-FICCIONAIS: A EXTERIORIDADE EM SILVIANO SANTIAGO
}

\author{
Pedro Henrique Alves de Medeiros* \\ Edgar Cézar Nolasco
}

RESUMO: Este trabalho tem por objetivo (re)ler o romance Mil rosas roubadas (2014) do escritor mineiro Silviano Santiago na esteira dos conceitos de amizade (DERRIDA, 2003) (ORTEGA, 2009), exterioridade (NOLASCO, 2015) (MIGNOLO, 2003) e homossexualidade (LOPES, 2002) (ORTEGA, 2002) sustentados por uma epistemologia Crítica biográfica fronteiriça por excelência. Por Crítica biográfica fronteiriça, entendemos a confluência dos estudos pós-coloniais com os críticobiográficos à luz de um lócus de enunciação brasileiro e exclusivamente latino-americano: a fronteirasul. Assim, nosso intuito é refletir acerca da obra supracitada nos valendo de reflexões pertinentes às subjetividades tanto do romance quanto, sobretudo, da relação deste com a vida do autor, um sujeito homossexual que pensa, produz e cria a partir desse lugar identitário-biográfico, dessas sensibilidades biográficas. Desse modo, nossa proposta se engendra em uma perspectiva compósita, transdisciplinar e metafórica oriunda da crítica biográfica (SOUZA, 2002) e, além disso, se assenta em uma visada transferencial entre nós críticos, também homossexuais, que pensamos da fronteira-sul do Brasil e o intelectual homossexual que erige sua literatura a partir de um lugar marcado pela exterioridade, isto é, uma produção artístico-cultural extrínseca aos preceitos modernos, heternormativos, hegemônicos e padronizados de subjetividade e identidade socialmente cristalizados. Para isso, nos valeremos de uma metodologia eminentemente bibliográfica assentada em teóricos, dentre outros, como Edgar Cézar Nolasco, Juliano Garcia Pessanha, Francisco Ortega, Jacques Derrida, Walter Mignolo, Eneida Maria de Souza e Denilson Lopes.

PALAVRAS-CHAVE: Crítica biográfica fronteiriça; Exterioridade; Homossexualidade; Mil rosas roubadas; Silviano Santiago.

Digo de maneira bem direta e simples: nós dois propúnhamos um modelo de vida conjugal, a ser imitado. [...] Meu desejo era tê-lo vinte e quatro horas como observador consentido, por isso privilegiado.

(SANTIAGO, 2014, p. 26-27)

\footnotetext{
* Mestrando em Estudos de Linguagens pela Universidade Federal do Mato Grosso do Sul (UFMS). Bolsista CAPES.

** Doutor em Literatura Comparada pela Universidade Federal de Minas Gerais (UFMG). Professor da Universidade Federal de Mato Grosso do Sul (UFMS). Atualmente desenvolve estágio de Pós-Doutorado no PACC na Universidade Federal do Rio de Janeiro (UFRJ). Membro do GT de Literatura Comparada da ANPOLL. Membro do conselho editorial das Revistas - Papéis (UFMS) e RAÍDO - Revista do Programa de Pós-Graduação em Letras Universidade Federal da Grande Dourados (UFGD).
} 
"Perco meu biógrafo. Ninguém me conheceu melhor que ele. Nascemos um para o outro aos dezesseis anos de idade, em Belo Horizonte, nos idos de 1952” (SANTIAGO, 2014, p. 07). Encoberto pelo manto fúnebre da morte do amigo-amado (DERRIDA, 2003) e alicerçado pelo que entendemos à luz de Jacques Derrida e Francisco Ortega por discurso do epitáfio, Silviano Santiago gira a chave ficcional para (des)arquivar suas memórias da exterioridade narrando pelo crivo da homo-bio-ficção suas/nossas Mil rosas roubadas (2014). Juliano Garcia Pessanha em Recusa do não-lugar (2018) afirma em um determinado poema que "Nasci[eu] surpreendido por saudade absurda" (PESSANHA, 2018, p. 90). Compreendemos, portanto que, metaforicamente, as Mil rosas roubadas a priori, por Silviano e, agora, por nós, se expõem ao mundo de maneira semelhante a do eu-lírico aposto.

Ensejamos neste texto (re)ler o romance Mil rosas roubadas (2014) do escritor, crítico e intelectual mineiro Silviano Santiago utilizando-nos dos conceitos de amizade (DERRIDA, 2003) (ORTEGA, 2009), exterioridade (NOLASCO, 2015) (MIGNOLO, 2003) e homossexualidade (LOPES, 2002) (ORTEGA, 2001) assentados em uma metodologia bibliográfica e respaldados pela teorização Crítica biográfica fronteiriça. Assim, dentre os teóricos que nos abalizam, podemos mencionar, a exemplo, Edgar Cézar Nolasco, Francisco Ortega, Jacques Derrida, Gloria Anzaldúa, Walter Mignolo, Eneida Maria de Souza e Denilson Lopes. Isso posto, sob o crivo epistemológico Nolasco ressalta:

A denominação CRÍTICA BIOGRÁFICA FRONTEIRIÇA merece uma nota explicativa. Em meu livro Perto do coração selbaje da crítica fronteriza (2013), como mostra o título, já me detinha acerca de uma crítica fronteiriça. Todavia, ali me valia mais da rubrica póscolonial ou pós-ocidental como forma de atender melhor aos postulados teóricos empregados. Não abri mão de tais teorias, muito pelo contrário. Mas entendo, agora, que elas se voltavam muito mais para uma América Latina como um todo e que, ao seu modo, continua a excluir o Brasil ou, quando não, este vinha meio a reboque. $\mathrm{Na}$ tentativa de resolver em parte isso que me incomodava, fechei um pouco mais o recorte epistemológico e, em contrapartida, como ganho teórico na discussão que proponho agora, aproximei-me mais do meu bios e do meu lócus, posto que a fronteira-sul daqui de onde penso é tão real quanto epistemológica. (NOLASCO, 2015, p. 47) 
Em linhas gerais, a teorização - e não teoria, explicaremos o porquê na sequência deste texto - Crítica biográfica fronteiriça congrega as reflexões advindas dos estudos póscoloniais e da crítica biográfica respaldadas pelo biolócus (bios + lócus) dos críticos que engendram suas reflexões teóricas. Erigimos nossas considerações a partir da fronteira-sul, lócus geoistórico ${ }^{1}$ e epistemológico, real e imaginário, a qual nos demanda um posicionamento crítico outro crivado em uma opção descolonial. Sob essa consciência, o olhar que lançamos para o romance Mil rosas roubadas, para Silviano Santiago e, sobretudo, para o seu projeto bomo-bio-ficcional é fomentado por essa consciência epistêmica descolonial e biográfica de maneira essencial ao que se refere às discussões sobre exterioridade, amizade e homossexualidade.

Todavia, antes de adentrarmos essa tríade conceitual a partir do bojo ficcional de Silviano, julgamos necessário entender a discussão da crítica biográfica fronteiriça enquanto uma teorização pensada e erigida a partir do biolócus sul-fronteiriço alicerçado por nossas sensibilidades de homem-fronteira homo-biográficos e não apenas como mera teoria disciplinar. Para Nolasco, as teorias pós-coloniais não dão conta das idiossincrasias de um pensamento que emerge não apenas de um lócus latino-americano como um todo, mas, primordialmente, brasileiro e sul-fronteiriço. $\mathrm{O}$ sentido atribuído à teoria não nos é produtivo na medida em que nos afastamos cada vez mais de estruturas disciplinares e redutoras. Para Mignolo, a teorizaçãa pós-colonial é "[...] um processo de pensamento que os que vivem sob a dominação colonial precisam empreender para negociar suas vidas e sua condição subalterna” (MIGNOLO, 2003, p. 145).

Nosso fazer epistêmico-fronteiriço está para além dos discursos alocados em nossas produções acadêmicas, visto que vivemos, sentimos e rivalizamos a fronteira-sul em nossos corpos e, ademais, existimos a partir de (MIGNOLO, 2003) uma exterioridade latente, assim como Silviano e sua/nossas Mil rosas roubadas. Somos críticos biográficos fronteiriços

\footnotetext{
${ }^{1}$ Geoistórico é um conceito discutido por Walter Mignolo em História locais/projetos globais (2003) na direção de (re)pensar os loci outros detentores de histórias e sensibilidades não contempladas pelos projetos globais coloniais.
} 
homossexuais propondo reflexões críticas e construindo uma persona um espectro de Silviano Santiago, também gay, nos valendo de um romance que narra formas de sociabilidade (ORTEGA, 1999) políticas outras de dois homens amigos-amantes. Dada essa aproximação metafórica, entendemos que transferencialmente nos aproximamos e nos distanciamos de Silviano e de seu projeto homo-bio-ficcional de maneira simbiótica e canibalizadora (PESSANHA, 2018). Falamos de nós através dele. Executamos o exercício (des)arquiviolítico a partir do arquivo homo-biográfico de Silviano que se abre com/a partir de nós.

Nossa perspectiva crítica se apropria do viés compósito e do metafórico (SOUZA, 2002, p. 111) da crítica biográfica ao diluir as fronteiras disciplinares entre vida/obra e teoria/ficção. Há o estabelecimento de pontes metafóricas entre fato e ficção ao englobarmos as complexas relações entre obra e autor, escritor e crítico (SOUZA, 2002). Criamos nossas formulações epistêmicas acerca de nossas Mil rosas roubadas na mesma medida em que somos criados por elas (PESSANHA, 2018). Sendo assim, a primeira acepção crítica que nos ajuda a (re)ler o romance de Silviano Santiago concerne ao conceito de exterioridade. Para tal, faz-se necessário repensarmos as questões de dentro e fora no que tange à nossa existência homo-biográfica:

Mas se a metafísica da presença pensou apenas o Dentro, devemos, agora, a começar a pensar o Fora. E devemos fazê-lo não porque isso seja apenas uma novidade ou um pensamento diferente no mercado das ideias. Não: pensar o Fora [...] [é] operar uma mutação na nossa maneira de existir. Somos, hoje, eticamente forçados a pensar diferente, porque estamos, pela primeira vez, numa situação capaz de perceber a violência e a agressão que dormitavam no pensamento metafísico. (PESSANHA apud NOLASCO, 2015, p. 48)

Com base na passagem de Pessanha, reiteramos a necessidade de pensarmos o Fora enquanto aquilo que foi desconsiderado pela história moderna, hegemônica, colonial e heterossexual europeia/norte-americana, isto é, a exterioridade criada pela interioridade. O discurso crítico academicista e disciplinar é exemplar em repetir teorias/narrativas itinerantes que grassam dos centros mundiais modernos para as bordas do planeta sem considerar as sensibilidades locais dos seus hospedeiros e, tampouco, seus loci geoistóricos. Narrativas de homens brancos, burgueses e heterossexuais se sustentam como temática universal no 
cerne dos estudos de literatura subsidiadas pela falácia de que estas histórias dão conta de narrar todas as histórias.

É sob a égide desse contexto colonial-moderno que tomamos Mil rosas roubadas (2014) na direção de um romance da exterioridade que escre(vi)ve (EVARISTO, 2017) através da abertura do arquivo de uma amizade real/ficcional as memórias de homens amigos-amantes que possuem sociabilidades extrínsecas à lógica dita universal e homogênea e que performatizam comportamentos que, a priori, não lhes seriam permitidos dado o princípio de masculinidade estabelecido pela interioridade patriarcal. Nossas sensibilidades e histórias se encontram com as de Silviano/Mil rosas roubadas em uma percepção de semelhança na diferença homo-biográfica. Ademais, o lócus geoistórico tanto de Silviano quanto do romance é também da ordem do Fora, uma vez que a história se passa em Belo Horizonte nos anos 1950 atravessada pela crescente urbanização mineira. Essa informação é importante em virtude da capital de Minas Gerais estar extrínseca ao eixo geoistórico central brasileiro Rio-São Paulo.

Assim, entendemos que tanto o bios quanto o lócus de Mil rosas roubadas, de Silviano Santiago e os nossos estão alocados em uma lógica não considerada pelos discursos vigentes como universais e padrões (interioridade). Nossas histórias locais, sensibilidades e opções bio-epistêmicas se (re)verificam em uma lógica não considerada pela colonialidade. Sociabilidades homoafetivas/ homo-biográficas de dividuos ${ }^{2}$ latino-americanos, brasileiros, sulfronteiriços/mineiros são amplamente rechaçadas e relegadas ao esquecimento por não serviram à lógica da interioridade que dissipa aquilo que destoa da norma. Nem nossos bios nem nossos loci servem aos preceitos ditados pelo Dentro, fomos/somos expurgados para as margens, para as bordas, para a exterioridade. No plano das questões que chamamos de homo-biográficas, Francisco Ortega em Genealogias da amizade (2002) nos explicita:

\footnotetext{
${ }^{2} \mathrm{O}$ conceito de divíduo pode ser encontrado na obra Recusa do não-lugar (2018) de Juliano Garcia Pessanha. Em linhas gerais, o dividuo dissipa a gramática sujeito-objeto para tomar essa relação simbiótica como uma relação de animação, de aliado hospitaleiro, de ser um-em-dois ou um-no-outro.
} 
A modernidade prolongou essa atitude de total abominação e condenação universal da homossexualidade, a qual se torna um problema médico e sociopolítico no século XIX, de tal maneira que até hoje é quase impossivel mostrar afeto nas relações de amizade, especialmente considerado homoerótico. 'Para dizerer 'te amo' a um amigo ou amiga é necessário atravessar até no próprio corpo inúmeras grades históricas, uma floresta imensa de proibições e distinções, códigos, cenários, posições". (DERRIDA apud ORTEGA, 2002, p. 91. Grifos nossos)

Diante desse excerto, compreendemos que o romance Mil rosas roubadas se insere na contracorrente da modernidade colonial (interioridade), uma vez que esta sempre primou pela exclusão da(s) afetividade(s) entre homens. Desde os passos iniciais do (des)arquivamento das memórias de Silviano tornadas narrativa, já visualizamos a declaração que é repetida mais de uma vez no texto "Nascemos um para o outro aos dezesseis anos de idade [...]" (SILVIANO, 2014, p. 07). Dentro da lógica colonial que dissipa as sensibilidades outras, esse tipo de afetividade sensível entre homens é enxergado como imprópria e até pecaminosa - tendo em vista que o pensamento moderno-colonial é essencialmente cristão. Silviano ao falar a partir de (MIGNOLO, 2003) uma exterioridade sensível, biolocal e epistêmica narra sua história de amizade/amor com seu amigo-amado político e quase biógrafo.

Podemos, portanto, (re)ler a relação de Silviano com Zeca em Mil rosas roubadas sob o crivo metafórico da liberdade de uma borboleta-azul que voa para além da floresta imensa de proibições e distinções, códigos, cenários e posições. A imagem da borboleta-azul é um ponto fundamental na (boa) amizade política entre os rapazes - conceito que desenvolveremos na sequência - uma vez que explicita um dos principais momentos de afetividade, pois, ao Zeca demonstrar interesse pelo exercício entomológico, Silviano se metaforiza em borboleta-azul a fim de chamar a intenção do amigo-amado: "Sinto-me uma borboleta-azul a esvoaçar em plena praça Sete. Ele riu” (SANTIAGO, 2014, p. 67)

Para nós, a borboleta-azul representa esse voo de liberdade sensível-epistêmico que Silviano aquilata ao escre(vi)ver sua amizade/relacionamento, real e ficcional, com Zeca, sobretudo, de maneira sensível e que (de)marca um estilo de vida gay em 1950 (ORTEGA, 1999, 154) para além das grades históricas abordadas por Ortega. Para Denilson Lopes em $O$ 
homem que amava rapazes (2002): "Ser um escritor gay é [...] uma forma de redefinir práticas políticas marcadas pelo cotidiano, uma ética de um sujeito plural e uma estética da existência" (LOPES, 2002, p. 28). Além disso, o lócus epistêmico o qual Silviano produz e escre(vi)ve, assim como nós críticos fronteiriços homo-biográficos, está extrínseco a um lugar plenamente aceito e considerado pelos universalismos modernos. A exterioridade se dá em e a partir de nossos corpos homo-biográficos e brasileiros sul-fronteiriços. Walter Mignolo, na esteira de Gloria Anzaldúa, pontua:

Anzaldúa mostra a necessidade uma epistemologia fronteiriça [...] que permita pensar e construir pensamento a partir dos interstícios e que possa aceitar que os [...] homossexuais são categorias fora da lei desde uma epistemologia monotópica que normaliza determinados espaços (nacionais, imperiais), como espaços de contenção e de marginalização. (MIGNOLO apud NOLASCO, 2015, p. 50: tradução nossa)

Nesse sentido, a partir do contexto da exterioridade o qual nossa (re)leitura se assenta, entendemos que um dos pontos elementares que concernem ao romance Mil rosas roubadas é substancialmente a óptica da (boa) amizade política, sob a égide, nas nossas reflexões, de Jacques Derrida e Francisco Ortega. Mil rosas roubadas (des)arquiva as memórias de Silviano (re)afirmando o que Derrida e Ortega entendem por discurso do epitáfio (DERRIDA, 2003) (ORTEGA, 2009). Em linhas gerais, o discurso do epitáfio explicita a possibilidade / um compromisso de uma amizade e um amor para além da morte e da vida (ORTEGA, 2009, p. 69). Nesse contexto, o amigo é cópia/imagem de mim/de nós assinando uma oração fúnebre (ORTEGA, 2009, p. 69). Derrida pontua:

Não poderei amar por amizade sem me comprometer, sem antecipadamente me sentir comprometido a amar o outro para além da morte. Logo, para além da vida. Sinto-me, e de antemão, antes de todo e qualquer contrato, levado [porté] a amar o outro morto. Sinto-me assim (levado a) [(porte a)] amar, é assim que me sinto (amar) A autologia dá que pensar, como sempre: sinto-me amar, levado a o morto [...]. (DERRIDA, 2003, p. 26)

Como explicitado, a declaração que abre as portas da narrativa das Mil rosas roubadas pode ser entendida, em menor ou maior grau, como uma espécie de oração fúnebre em 
relação à morte do amigo-amado. Sumariamente, a perda, a morte e a tentativa de lidar com a falta de um amigo amado delineiam o (des)arquivamento memorialístico de Silviano no romance aposto. Constitui-se uma amizade para além da vida a qual, a prioris a ausência se torna presença subsidiada pelo discurso ficcional de Silviano e agora pelo epistêmico ensejado por nós críticos biográficos fronteiriços.

Para Jacques Derrida em Politicas da amizade (2003) “[...] é preciso partir do amigoamante e não e não do amigo-amado para pensar a amizade" (DERRIDA, 2003, p. 23). É crivado na óptica do amigo-amado que Silviano narra sua história com Ezequiel Neves (re)afirmando de modo derridiano a possibilidade de Mil rosas roubadas se projetar enquanto um romance, essencialmente, sobre a amizade, mas também, acerca das sociabilidades homobiográficas, das reflexões relacionadas ao ato de biografar e, dentre outras, do trabalho de luto daquele que sobrevive à morte do amado. Há uma tentativa de lidar com a sombra fantasmagórica da morte (real/ficcional) alicerçada pelo discurso literário-epistêmico de uma ficção teórica. Valendo-se da memória faltosa, lacunar e falha, Silviano supre essas faltas ficcionalmente a fim de narrar sua escrevivência homo-biográfica com Zeca a partir de sua (boa) amizade política. Por esse tipo de relação, entendemos:

A boa amizade supõe a desproporção. Exige uma certa ruptura de reciprocidade ou de igualdade [...] A boa amizade nasce da desproporção quando se estima ou respeita (achtet) o outro mais do que a si mesmo - e eis aqui uma segunda partilha, na amância, entre a amizade e o amor. A boa amizade supõe, claro, um certo ar, um certo toque (Anstrich) de intimidade, mas uma intimidade sem intimidade propriamente dita. (DERRIDA, 2003, p. 74)

Silviano e Zeca são, aos nossos olhos, amigos políticos na medida em que não (re)produzem um modelo fraternal de amizade, eles não apenas (re)afirmavam suas subjetividades um pelo outro, mas, politicamente, pelas personalidades e comportamentos extremamente opostos, transformavam-se pelos confrontos, pelos atritos ou, pelo que o próprio romance expõe, pelos desentendimentos passageiros e profundos (SANTIAGO, 
2014, p. 215) estabelecendo o que os intelectuais da amizade supracitados entendem como o processo de ascese $^{3}$ (DERRIDA, 2003) (ORTEGA, 2001).

A amizade, nesse prisma, representa um apelo a novas formas de experimentações de sociabilidades, um exercício do político, uma busca por alternativas alheias às normas tradicionais de relacionamentos (ORTEGA, 2001, p. 23). Silviano e Zeca explicitam escolhas de vida extremamente distintas, ficcional e biograficamente, visto que aquele, à nossa semelhança enquanto críticos e professores, opta por seguir a carreira acadêmica, dedicarse à aposentadoria e à calmaria de uma vida comum, já Ezequiel escolhe experienciar os paraísos artificiais dos anos 1950, debruçar-se sobre as boêmias do mundo e, de maneira descortinada, levar a vida na posição de um artista sem grandes preocupações institucionais. Silviano e Zeca "co-habitam" lados distintos de uma mesma moeda homo-biográfica em que suas aproximações político-afetivas são crivadas na diferença.

Ainda no que convém ao plano da diferença entre os amigos-amantes, julgamos necessário pontuar, conforme a ideia de aproximar-se pela semelhança na diferença, que os amigos possuíam personalidades opostas e que em demasiados momentos se confrontavam não desestruturando, com isso, a amizade que, se alocada em uma perspectiva fraternalista e não transformadora, pudesse entrar em ruínas. $\mathrm{O}$ modo de sociabilidade político e homo-biográfico que Silviano e Zeca promoviam nos leva a compreender que a discórdia não deve ser considerada como algo que desestruture uma relação, mas que a fortaleça. Silviano afirma:

Demonstrava coragem suficiente para afirmar - diante de possível e inconveniente ruptura na amizade - que a discórdia entre amigos não deve ser considerada como algo de estranho à expansão infinita dos sentimentos fraternos. Aliás, acrescentava, que no terreno apimentado pelos afetos, há sempre que abrir espaço para os desentendimentos passageiros e profundos. (SANTIAGO, 2014, p. 215)

\footnotetext{
${ }^{3}$ Francisco Ortega, à luz de Foucault, em Amizade e estética da existência em Foucault entende a ascese enquanto a capacidade de efetuar determinadas operações sobre si para se transformar e propor para si uma forma de existência (ORTEGA, 1999, p. 23).
} 
Sob a pluma de todas as reflexões apostas e já nos encaminhando para a conclusão deste trabalho, a exterioridade se apresenta como um lugar posto em nós, em nossos corpos bomo-biográficos, em nossas reflexões epistêmicas e, sobretudo, em nossos projetos homo-bioficcionais. Silviano pensa, produz e escrever a partir de uma consciência que se abre para uma possibilidade descolonial crivada e subsidiada por uma escrevivencia (EVARISTO, 2017) de homem gay erigindo suas produções à luz de suas sensibilidades, de seu biolócus e do seu próprio corpo homo-biográfico tal qual fazemos nós, críticos biográficos fronteiriços, que pensamos, sentimos e falamos de um lugar outro, subalterno e marginalizado: a fronteirasul.

Conceição Evaristo em determinada entrevista propõe que “[...] todos fazem uma escrevivência, a partir da escolha temática, do vocabulário que se usa, do enredo a partir de suas vivências e opção" (EVARISTO, 2017, s/p). Por isso, entendemos que a escrevivência de Silviano e também a nossa se aproximam e se distanciam, uma vez que escrevi(ve)mos a partir de experiências e sensibilidades biolocais específicas dos nossos próprios corpos políticos. Mil rosas roubadas enquanto um romance que (des)arquiva memórias fúnebres sobre/a partir da perda de um amigo-amor-político, fala marcadamente desse lugar outro (do Fora) não contemplado nem politicamente pelos padrões modernos, coloniais e patriarcais, nem pelas formas de existências, experiências e sociabilidades políticas construídas culturalmente - fraternas e não transformadoras. Ortega, nesse sentido, corrobora:

Ao passo que a amizade foi aceita social e culturalmente, a homossexualidade não representava problema, mas, desde que amizade se desfaz como forma de relação tolerada culturalmente, a seguinte pergunta torna-se atual: "Que fazem os homens juntos?”. A homossexualidade torna-se um problema médico e sociopolítico. [...] A amizade tem, para Foucault, principalmente o sentido de uma amizade homossexual. Sua atenção concentra-se, principalmente, nas possibilidades disponíveis hoje na cultura homossexual para criar novas formas de amizade. (ORTEGA, 1999, p. 165)

Por fim, Denilson Lopes em O homem que amava rapaz̧es (2002) expõe que Silviano Santiago é um dos críticos/escritores desta geração que mais contribui/contribuiu para os estudos gays no Brasil. Para ele: "Silviano descortina o horizonte de uma sociedade em que 
outras diferenças foram excluídas [...]" (LOPES, 2002, p. 31-32). Isso posto, Mil rosas roubadas extrapola os limites culturais, políticos e sociais ao transpor para a figura do narrador homem o (des)arquivamento de suas memórias com/sobre o amigo-amado na tentativa de lidar com a perda e, consequentemente, com a ausência deste. A ausência, portanto, se torna presença na medida em que Silviano desloca a figura da morte do lugar de fim (re)alocando-a como uma possibilidade de início. A morte é a chave que ao ser girada por Silviano usurpa para si as Mil rosas roubadas e dá o tom inicial de um romance que, por vezes, deixa de ser um romance canonicamente concebido. Mas sim, uma tentativa bomo-bio-ficcional de tentar lidar com a sombra fantasmagórica da morte que usurpa o amado do amante relegando a este a sobrevivência crivada pela falta.

\title{
A THOUSAND HOMO-BIO-FICTIONAL ROSES: THE EXTERIORITY IN SILVIANO SANTIAGO
}

\begin{abstract}
This work aims to (re)read the novel Mil rosas roubadas (2014) by the writer Silviano Santiago in the wake of the concepts of friendship (DERRIDA, 2003) (ORTEGA, 2009), exteriority (NOLASCO, 2015) (MIGNOLO, 2003) and homosexuality (LOPES, 2002) (ORTEGA, 2002) supported by a Critical biographical epistemology frontier by excellence. By cross-border biographical critique, we understand the confluence of postcolonial studies with biographical critics in the light of a locus of Brazilian and exclusively Latin American enunciation: the south-frontier. Thus, our intention is to reflect on the aforementioned work using reflections pertinent to the subjectivities of both the novel and, above all, the relation of this with the life of the author, a homosexual subject who thinks, produces and creates from this identity-biographical place, biographical sensibilities. Thus, our proposal is engendered in a composite, transdisciplinary and metaphorical perspective derived from biographical criticism (SOUZA, 2002) and, moreover, it is based on a transferential view among critical, homosexuals, who think of the southern border of Brazil and the homosexual intellectual who erects his literature from a place marked by externality, that is, an artistic-cultural production extrinsic to the modern, hetero-normative, hegemonic and standardized precepts of socially crystallized subjectivity and identity. To that end, we will use an eminently bibliographical methodology based on theorists, among others, such as Edgar Cézar Nolasco, Juliano Garcia Pessanha, Francisco Ortega, Jacques Derrida, Walter Mignolo, Eneida Maria de Souza and Denilson Lopes.
\end{abstract}

KEYWORDS: Critical biographical frontier; Exteriority; Homosexuality; Mil rosas roubadas; Silviano Santiago.

\section{REFERÊNCIAS}

DERRIDA, Jacques. Políticas da amizade: seguido de o ouvido de Heidegger. Porto: Campo das Letras, 2003. 
EVARISTO, Conceição. Em entrevista ao 'Nexo', escritora fala sobre memória, vivência, escrita e os avanços e lutas do movimento negro. Disponível em: https://www.nexojornal.com.br/entrevista/2017/05/26/Concei $\% C 3 \%$ A7\%C3\%A3o-Evaristo-

$\% \mathrm{E} 2 \% 80 \% 98$ minha-escrita- $\% \mathrm{C} 3 \% \mathrm{~A} 9$-contaminada-pela-condi $\% \mathrm{C} 3 \% \mathrm{~A} 7 \% \mathrm{C} 3 \% \mathrm{~A} 3 \mathrm{O}-\mathrm{de}-$ mulher-negra $\%$ E2\%80\%99. Acesso em: 20 abr. 2019.

LOPES, Denilson. O homem que amava rapazes: e outros ensaios. Rio de Janeiro: Aeroplano, 2002.

MIGNOLO, Walter. Histórias locais/projetos globais: colonialidade, saberes subalternos e pensamento liminar. Belo Horizonte: Editora UFMG, 2003.

NOLASCO, Edgar Cézar. Crítica biográfica fronteiriça (Brasil/Paraguai/Bolívia). CADERNOS DE ESTUDOS CULTURAIS: Brasil/Paraguai/Bolívia, Campo Grande: UFMS, v. 7, n. 14, p. 47-63, jul./dez. 2015.

ORTEGA, Francisco. Genealogias da amizade. São Paulo: Editora Iluminuras, 2002.

ORTEGA, Francisco. Amizade e estética da existência em Foucault. Rio de Janeiro: Editora Graal, 1999.

ORTEGA, Francisco. Para uma politica da amizade: Arendt, Derrida, Foucault. Rio de Janeiro: Relume Dumará, 2009.

SANTIAGO, Silviano. Mil rosas roubadas. São Paulo: Companhia das Letras, 2014.

PESSANHA, Juliano Garcia. Recusa do não-lugar. São Paulo: Editora UBU, 2018.

SOUZA, Eneida Maria de. Crítica cult. Belo Horizonte: Editora UFMG, 2002.

Recebido em: 04/02/2020. Aprovado em: 20/05/2020. 